\title{
Procedural justice and egalitarian principles for rationing decisions in the COVID-19 crisis
}

\author{
Alexander Supady ${ }^{1,2,3^{*}}$ (D), Christoph Bode ${ }^{1,2}$ and Daniel Duerschmied ${ }^{1,2}$
}

In their insightful editorial on the justification for extracorporeal membrane oxygenation (ECMO) treatment in the coronavirus disease 2019 (COVID-19) pandemic, Abrams et al. argue for a utilitarian principle "reserving ECMO only for those patients who are most likely to derive benefit"-and consequently withholding ECMO from others with less desirable prospects [1]. We doubt that the utilitarian approach is appropriate in this context; therefore, we would like to suggest an alternative approach.

Norman Daniels developed "a theory of justice and health" that may help to make fair resource allocation decisions for ECMO during the COVID-19 pandemic [2]. In contrast to allocating resources solely guided by expected outcomes and maximization of net utility, Daniels proposes a focus on a fair process for making resource allocation decisions. Characteristic elements of this process called "accountability for reasonableness" are transparency and participation. In short, decisions and their rationales must be publicly accessible (publicity condition), they must be based on objective evidence or reasons and principles generally accepted as relevant (relevance condition), mechanisms for appeal and revision of decisions need to be in place (revision and appeals condition), and mechanisms to control and guarantee compliance with these principles must be established (regulative condition) [2].

Adoption of these principles for triage for or against ECMO therapy during the COVID-19 pandemic will help to unburden physicians from rationing decisions when treating their patients and to raise acceptance for necessary limitations. The practical application of these principles can well be done by triage committees as being installed in New York [3]. As described previously, members of these committees must be free of competing interests; this includes that they cannot be involved in the treatment of the patient the committee decides about. However, it seems equally necessary to set up these committees in such a way that their decisions are public and transparent and allow for public participation-the role of juries or lay assessors in court may serve as an example to find a structure fulfilling these demands.

It is not possible within the limited scope of this letter to describe a comprehensive account for fair setting of health care limits in a crisis like the coronavirus pandemic nor to describe in detail a fair process for limit setting and triage for ECMO therapy in COVID-19, but we encourage further thoughts about Daniels' "accountability for reasonableness" as a basis for deliberations on a fair distribution of limited health care resources.

This comment refers to the article available at https://doi.org/10.1186/ s13054-020-03230-9.

* Correspondence: alexander.supady@universitaets-herzzentrum.de

${ }^{1}$ Department of Medicine III (Interdisciplinary Medical Intensive Care), Medical

Center - University of Freiburg, Faculty of Medicine, University of Freiburg,

Freiburg, Germany

${ }^{2}$ Department of Cardiology and Angiology I, Heart Center, University of

Freiburg, Hugstetter Strasse 55, 79106 Freiburg, Germany

Full list of author information is available at the end of the article 


\section{Authors' response}

\section{Darryl Abrams, Roberto Lorusso, Jean-Louis Vincent, and Daniel Brodie}

We thank the authors for their thoughtful reply to our article "ECMO during the COVID-19 pandemic: when is it unjustified?" [1], in which they suggest the use of triage committees to ensure fair allocation of ECMO during the COVID-19 pandemic, an issue we raised in our article. We also appreciate the greater focus given to this important issue by the authors. Their intention of designing a system emphasizing transparency and objectivity of decision making is laudable. However, its use in allocating ECMO for COVID-19-associated severe respiratory failure would be complicated and in many ways may prove to be impractical. This is particularly clear during the resource constrained stage of a pandemic, where crisis standards of care are in place and precisely when such a system would be needed. Importantly, the triage committees the authors cite as having been deployed in New York [3] were never actually put in place because of the controversy they generated and the difficulty meeting the conditions set out by the authors as a framework for resource allocation, speaking volumes about the complexity of the undertaking. In jurisdictions where they were attempted, they were met with controversy and lawsuits [4].

If, after years of preparation for just such a scenario, triage committees in many instances could not be successfully implemented for allocation of ventilators, which are a widely accepted form of life support, then doing the same for ECMO, where agreement regarding indications and contraindications is less well established particularly in COVID-19 (the "relevance condition" cited by the authors), would be even more unlikely. We agree with the authors that, ideally, we should strive for a method of equitably distributing limited healthcare resources during a crisis, such as that proposed by Daniels, although doing so will clearly require a triage system that is both workable and acceptable to society at large. It will also require a thorough understanding of the benefits and limitations of the resource being considered, a condition that would be difficult to meet in the case of ECMO at the present time. In the end, a faulty triage plan based on insufficient data may be worse than no triage plan at all [5].

\section{Acknowledgements}

None.
Funding

None.

Availability of data and materials

Not applicable.

Ethics approval and consent to participate

Not applicable.

Consent for publication

Not applicable.

Competing interests

Not applicable.

\section{Author details}

${ }^{1}$ Department of Medicine III (Interdisciplinary Medical Intensive Care), Medical Center - University of Freiburg, Faculty of Medicine, University of Freiburg,

Freiburg, Germany. ${ }^{2}$ Department of Cardiology and Angiology I, Heart Center, University of Freiburg, Hugstetter Strasse 55, 79106 Freiburg, Germany. ${ }^{3}$ Heidelberg Institute of Global Health, University of Heidelberg, Heidelberg, Germany.

Received: 26 August 2020 Accepted: 14 September 2020

Published online: 29 September 2020

References

1. Abrams D, Lorusso R, Vincent JL, Brodie D. ECMO during the COVID-19 pandemic: when is it unjustified? Crit Care. 2020;24(1):507. https://doi.org/ 10.1186/s13054-020-03230-9.

2. Daniels N. Just health: meeting health needs fairly. Cambridge: Cambridge University Press; 2008.

3. Truog RD, Mitchell C, Daley GQ. The toughest triage - allocating ventilators in a pandemic. N Engl J Med. 2020;382(21):1973-5.

4. Klitzman RL: Legal immunity for physicians during the COVID-19 pandemic. Chest 2020:[Epub ahead of print].

5. Guest T, Tantam G, Donlin N, Tantam K, McMillan H, Tillyard A. An observational cohort study of triage for critical care provision during pandemic influenza: 'clipboard physicians' or 'evidenced based medicine'? Anaesthesia. 2009:64(11):1199-206.

\section{Publisher's Note}

Springer Nature remains neutral with regard to jurisdictional claims in published maps and institutional affiliations. 